\title{
An investigation about chronic prostatitis in ankylosing spondylitis
}

\author{
Eduardo Deves ${ }^{1,2}$, Rodrigo Novotny ${ }^{1,2}$, Fernando Hartmann Barazzetti ${ }^{3}$, Mara Cristina Scheffer ${ }^{3}$, \\ Letícia Kramer Pacheco ${ }^{3}$, Adriana Fontes Zimmermann ${ }^{4}$, Ivânio Alves Pereira ${ }^{4}$, Maria Luiza Bazzo ${ }^{3}$ and \\ Fabricio Souza Neves ${ }^{2,5,6^{*}}$ (D)
}

\begin{abstract}
Background: Chronic prostatitis has been a common disease reported with high frequency in ankylosing spondylitis (AS) even from decades ago. Infectious (Chlamydia trachomatis) or non-infectious (uric acid) prostatitis can hypothetically trigger vertebral inflammation in AS. This study aimed to assess the features of chronic prostatitis in patients with AS compared to healthy controls.

Methods: A cross-sectional study including male patients with AS and healthy controls who agreed to undergo a prostate examination was conducted. Structured clinical interviews, prostate physical examinations, and cytological, biochemical, and microbiological tests on urinary samples collected before and after standardized prostatic massage (pre- and post-massage test) were performed.

Results: Ninety participants (45 AS patients, mean age: $52.5 \pm 10.0$ years, with longstanding disease, $12.4 \pm 6.9$ years, and 45 controls, mean age: $52.8 \pm 12.1$ years) were included. National Institutes of Health - Chronic Prostatitis Symptom Index (NIH-CPSI) scores were similar in the AS and control groups (4.0 [1.0-12.0] vs. 5.0 [1.0-8.5], $p=$ 0.994). The frequencies of symptoms of chronic prostatitis ( $\mathrm{NIH}$-CPSI Pain Domain $\geq 4$ ) were also similar in both groups ( $23.3 \%$ vs. $22.7 \%, p=0.953)$. Results of polymerase chain reaction tests for Chlamydia trachomatis were negative in all tested urinary samples, and uric acid concentrations and leukocyte counts were similar in all pre- and post-massage urinary samples.
\end{abstract}

Conclusions: In this study, chronic prostatitis occurred in male patients with AS, but its frequency and characteristics did not differ from those found in the healthy male population of similar age.

Keywords: Ankylosing spondylitis, Pelvic pain, Prostatitis, Chlamydia trachomatis, Uric acid

\section{Background}

Ankylosing spondylitis (AS) is the most common form of spondyloarthritis, mainly affecting the sacroiliac joints and spine. In severe cases, it can even cause progressive calcification and ankylosis, often in an ascending nature through its longitudinal ligaments. In addition, extra-articular manifestations may also occur, such as uveitis [1].

\footnotetext{
* Correspondence: fabricio.souza.neves@ufsc.br

${ }^{2}$ Graduate Program in Medical Sciences (PPGCM), Health Sciences Center

(CCS), Federal University of Santa Catarina (UFSC), Florianópolis, Brazil

${ }^{5}$ Internal Medicine Department, Health Sciences Center (CCS), Federal

University of Santa Catarina (UFSC), Florianópolis, Brazil

Full list of author information is available at the end of the article
}

In 1958, Mason et al. described a strikingly high frequency $(83 \%)$ of prostatitis in men with AS based on the cytological analysis of urethral fluids obtained after prostatic massage [2]. However, these results have never been reproduced since then. More recently, an Icelandic survey identified prostatitis in $27 \%$ of male patients with AS based on medical record reviews, and the authors suggested that prostatitis was the second most frequent extra-articular manifestation of AS [3].

Chronic prostatitis could not only be a consequence of AS, but also a cause of the disease. It is hypothesized that the spread of pathogen-associated molecular patterns (PAMPs) or damage-associated molecular patterns

(c) The Author(s). 2021 Open Access This article is licensed under a Creative Commons Attribution 4.0 International License, which permits use, sharing, adaptation, distribution and reproduction in any medium or format, as long as you give appropriate credit to the original author(s) and the source, provide a link to the Creative Commons licence, and indicate if changes were made. The images or other third party material in this article are included in the article's Creative Commons licence, unless indicated otherwise in a credit line to the material. If material is not included in the article's Creative Commons licence and your intended use is not permitted by statutory regulation or exceeds the permitted use, you will need to obtain permission directly from the copyright holder. To view a copy of this licence, visit http://creativecommons.org/licenses/by/4.0/. 
(DAMPs) through the pelvic and vertebral lymphatic vessels from chronic prostate inflammation caused by an infectious (Chlamydia trachomatis) or non-infectious agent (uric acid) could induce vertebral inflammation [4].

To the best of our knowledge, the characteristics of prostatitis in AS patients have yet to be investigated and compared to a healthy control group using current standardized clinical and laboratory procedures to specifically assess these hypotheses.

The current classifications of chronic prostatitis were established in 1999 by the US National Institutes of Health $(\mathrm{NIH})$ as the following: chronic bacterial prostatitis (CBP, NIH category II), inflammatory chronic prostatitis/chronic pelvic pain syndrome (CP/CPPS, NIH category IIIa), and non-inflammatory $\mathrm{CP} / \mathrm{CPPS}$ (NIH category IIIb) [5]. The Meares-Stamey 4-glass test [6] or its simplified version by the Nickel's 2-glass test [7], also known as the pre- and post-massage test (PPMT), are the standard criteria for diagnosis using urinary samples collected after prostatic massage, in which NIH category II is confirmed with positive bacteriological culture results and NIH category IIIa with positive leukocyte counts. However, most men with chronic prostatitis symptoms are classified as NIH IIIb, with negative cultures and normal leukocyte counts at PPMT given the lack of biomarkers for this condition.

In this study, we first aimed to assess whether chronic prostatitis symptoms were more frequent or more severe, and whether urinary leukocyte counts at PPMT were higher in patients with AS than in healthy controls. Second, we also aimed to evaluate uric acid concentrations, bacterial growth, and presence of Chlamydia trachomatis in urinary samples obtained after prostatic massage in order to investigate possible causes of chronic prostatitis in this group.

\section{Methods}

We conducted a cross-sectional study including all male patients with AS attending an outpatient rheumatology public service who agreed to undergo prostate examination between 2015 and 2019. To be included in this study, these patients needed to fulfill the 1984 New York modified criteria for AS [8]. Exclusion criteria included the acute presence of urinary symptoms, use of antibiotics in the last 30 days, use of uric acid-lowering therapy, use of diuretics, and any previous diagnosis of prostatic disease. The control group comprised volunteers who attended the outpatient urology service, presenting without any current disease for prostate cancer screening.

All participants were interviewed using the validated versions of the National Institutes of Health - Chronic Prostatitis Symptom Index (NIH-CPSI) [9], International Prostate Symptom Score (IPSS) [10] and, in the AS group, the Bath Ankylosing Spondylitis Disease Activity Index (BASDAI) [11], with further calculation of Ankylosing Spondylitis Disease Activity Score (ASDAS) [12] based on serum C-reactive protein (CRP) levels (nephelometry). Erythrocyte sedimentation rate (ESR) (Westergren) and serum prostate-specific antigen (PSA) were also measured (chemiluminescence) prior to prostate palpation. Participants were defined as having prostatitis symptoms if they expressed concern of perineal pain or discomfort, and their NIH-CPSI pain domain score (ranging from 0 to 21) was $\geq 4$ [13]. These cases were also defined as having moderate to severe prostatitis symptoms if their NIH-CPSI pain domain scores were $\geq 8$ [14].

The prostate physical examination was performed in all participants by an experienced urologist (ED or $\mathrm{CN}$ ), with a 30-s standardized prostatic massage procedure. Midstream urine samples were collected immediately before and after the prostatic massage. Leukocyte counts were performed in Neubauer chambers, cultures were performed with the seeding of urine samples in the growth medium ChromID CPS ${ }^{\circ}$ (Biomerieux, France), and uric acid urinary concentrations were measured by uricase reaction. Polymerase chain reaction (PCR) assays for Chlamydia trachomatis were also performed in postmassage urinary samples of AS patients using GeneXpert CT/NG (Xpert) $)^{\circ}$ (Cepheid, USA) assay. Clinical and laboratory data of participants with positive microbiological test results (cultures or PCR) were then analyzed separately from the whole group.

This study was approved by the National Committee on Ethics in Research $(44,333,115.0 .0000 .0121)$, and a written informed consent was obtained from all patients. The sample size was estimated as 41 participants in each group in order to verify a difference of two points in the median NIH-CPSI score (from 4 to 6 ) with a $95 \%$ confidence level and $80 \%$ statistical power. Statistical analysis was performed using IBM SPSS ${ }^{\circ}$ v20.0. Normality of data distribution was tested using the KolmogorovSmirnov test, and the normally distributed data are presented as mean \pm standard deviation, in which differences between means were tested by Student's t-test. Non-parametric data are presented as median interquartile ranges, and the differences between medians were evaluated by Mann-Whitney $U$ test. Additionally, differences between proportions were tested using the chisquare test.

\section{Results}

Ninety men were included, including 45 patients with AS and 45 controls. Regarding microbiological examination, all tested urinary samples (post-massage urine in the AS group) showed negative results for C. trachomatis. The cultures showed positive results with more than $10^{5}$ colony-forming units $(\mathrm{CFU}) / \mathrm{mL}$ in both pre- and 
post-massage samples (suggesting bacterial cystitis) in two participants - one AS patient with Escherichia coli and one control with Enterococcus faecalis. The culture result was positive in the post-massage sample and negative in the pre-massage sample (suggesting bacterial prostatitis) in one AS patient with Enterococcus faecalis. These patients were treated as indicated and excluded from further analysis. The clinical and blood laboratory data of the participants included in the study are presented in Table 1. All AS patients underwent regular treatment, and those who were not under treatment with anti-tumor necrosis factor (TNF) agents were using different combinations of non-steroidal antiinflammatory drugs (NSAIDs) and non-biological disease-modifying antirheumatic drugs (DMARDs).

The urinary data comparison between the groups is presented in Table 2. All cases with symptoms of prostatitis in the AS group had leukocyte counts in postmassage samples lower than $20,000 / \mathrm{mm}^{3}$ and were classified as non-inflammatory chronic prostatitis/chronic pelvic pain syndrome (CP/CPPS, NIH-IIIb).

\section{Discussion}

In our study, $23.3 \%$ of patients with AS had symptoms of chronic prostatitis (NIH-CPSI pain scores $\geq 4$ ), which resembled the frequency of chronic prostatitis (27\%) described in the 2010 epidemiological study conducted in

Table 1 Clinical characteristics and blood laboratory tests of AS patients and controls (excluding participants with positive urinary cultures - two in the AS group and one in the control group)

\begin{tabular}{llll}
\hline & AS $(\boldsymbol{n}=\mathbf{4 3})$ & Controls $(\boldsymbol{n}=\mathbf{4 4})$ & $\mathbf{p}$ \\
\hline Age (years) & $52.5 \pm 10.0$ & $52.8 \pm 12.1$ & 0.882 \\
Disease duration (years) & $12.4 \pm 6.9$ & & \\
Anti-TNF treatment & $35(86.0 \%)$ & & \\
BASDAI & $4.9 \pm 1.7$ & & \\
ASDAS & $2.7 \pm 0.6$ & & 0.944 \\
NIH-CPSI & $4.0[1.0-12.0]$ & $5.0[1.0-8.5]$ & 0.953 \\
NIH-CPSI (Pain Domain) $\geq 4$ & $10(23.3 \%)$ & $10(22.7 \%)$ & 0.716 \\
NIH-CPSI (Pain Domain) $\geq 8$ & $6(14.0 \%)$ & $5(11.4 \%)$ & 0.105 \\
IPSS & $6[2.5-13.5]$ & $2.5[0.0-12.0]$ & 0.499 \\
IPSS > 8 & $14(32.6 \%)$ & $13(29.5 \%)$ & 0.324 \\
PSA (ng/mL) & $1.2 \pm 1.1$ & $1.8 \pm 2.0$ & $\mathbf{0 . 0 1 1}$ \\
CRP (mg/L) & $3.2[2.8-3.3]$ & $2.3[1.0-2.6]$ & 0.857 \\
ESR (mm/h) & $4[3-5]$ & $3[2-5]$ & 0.624 \\
Uric acid (mg/dL) & $5.8 \pm 1.3$ & $5.5 \pm 1.2$ & \\
\hline
\end{tabular}

ASDAS Ankylosing spondylitis disease activity score, AS Ankylosing spondylitis, BASDAl Bath ankylosing spondylitis disease activity index, NIH-CPSI National Institutes of Health - Chronic Prostatitis Symptom Index, IPSS International Prostate Symptom Score, PSA Prostate-specific antigen, TNF Tumor necrosis factor, CRP C-reactive protein, ESR Erythrocyte sedimentation rate. Data are presented as mean \pm standard deviation (for normally distributed data), median [interquartile range] for non-parametric data
Iceland [3]; however, chronic prostatitis symptoms were equally frequent in the control group (22.7\%) of our study. The frequencies of moderate to severe prostatitis symptoms (NIH-CPSI pain scores $\geq 8$ ) were also similar between the AS (14.0\%) and control groups (11.4\%), which resembled the overall prevalence of chronic prostatitis in the general male population, estimated to be $8.2 \%$ [15]. The median values of the NIH-CPSI and IPSS scores were also compared between the AS and control groups. In our study, post-massage urinary leukocyte counts were not elevated in chronic prostatitis cases in the AS group, which meant that all of them could be classified as non-inflammatory chronic prostatitis $(\mathrm{NIH}-$ IIIb classification). This was the most frequent form of chronic prostatitis and was recently conducted to the broader definition of "chronic pelvic pain syndrome" (CPPS) for this entity [16]. Thus, the characteristics of the chronic prostatitis cases in AS patients described in our study were quite similar to those expected in the general adult male population. Our results suggested that chronic prostatitis was a frequent finding in the adult male population, irrespective of the presence of AS.

Our findings did not support the pioneering study by Mason et al., which described an impressive frequency of $83 \%$ of chronic prostatitis, defined by the presence of $\geq 10$ polymorphonuclear leukocytes per high-power microscopy field in post-massage prostatic fluids [2]. Leukocyte counts in the post-massage samples were similar in the AS and control groups in our study. However, we may consider that current treatment of AS with anti-TNF agents may also be a therapy for chronic prostatitis, and they could have influenced our results, reducing the severity of prostatitis in the AS group (86.0\% of AS patients were using anti-TNF agents) [17]. Another possible confounding factor in our study was the fact that our control group was composed of healthy men who were interested in the prostatic cancer screening. This could have led to a bias in our control group toward a higher severity of prostatitis symptoms. Before making any definitive conclusions, we believe that our findings need to be reassessed by other investigators.

Our study did not identify the etiologic factors that we tested as causative agents of prostatitis in patients with AS. All post-massage urinary samples showed negative results for $C$. trachomatis in a highly sensitive PCR assay, and uric acid concentrations did not differ between pre- and post-massage urine samples. Thus, our results did not support the hypothesis that spreading of PAMPs or DAMPs from the prostate contributes to the pathogenesis of AS [4]. However, the long duration of disease in our study group may have diminished urinary findings that could have been present in the early course of untreated disease. Prostate assessment in the early 
Table 2 Comparison of pre- and post-massage urinary tests between AS patients and healthy controls (excluding participants with positive urinary cultures)

\begin{tabular}{|c|c|c|c|c|c|c|}
\hline & pre-massage & & & post-massage & & \\
\hline & AS & control & $p$ & AS & control & $p$ \\
\hline Leukocyte count $\left(/ \mathrm{mm}^{3}\right)$ & 2000 [1000-6000] & 2000 [1000-5250] & 0.603 & 3000 [2000-5000] & 3000 [1000-11,475] & 0.704 \\
\hline Uric acid (mg/dL) & $53.3 \pm 29.4$ & $54.9 \pm 24.8$ & 0.782 & $55.3 \pm 24.9$ & $51.2 \pm 28.9$ & 0.480 \\
\hline
\end{tabular}

AS Ankylosing spondylitis; Data are presented as mean \pm standard deviation (for normally distributed data) or median [interquartile range] for non-parametric data

and untreated AS or undifferentiated spondyloarthtitis could be a field for further research.

\section{Conclusions}

In the present study, chronic prostatitis/chronic pelvic pain syndrome (CP/CPPS) occurred in male patients with longstanding ankylosing spondylitis (AS) under standard treatment (mainly based on anti-TNF agents); however, in this population, the frequency and characteristics of prostatic disease did not differ from those found in healthy controls of similar age.

\section{Abbreviations}

AS: Ankylosing spondylitis; ASDAS: Ankylosing Spondylitis Disease Activity Score; BASDAI: Bath Ankylosing Spondylitis Disease Activity Index; CP/ CPPS: Chronic prostatitis / Chronic pelvic pain syndrome; CPSI: Chronic Prostatitis Symptom Index; DAMP: Damage-associated molecular pattern; IPSS: International Prostate Symptom Score; NIH: National Institutes of Health; PAMP: Pathogen-associated molecular pattern; PPMT: Pre- and post-massage test

\section{Acknowledgements}

Hospital Universitário Prof. Polydoro Ernani de São Thiago / Universidade Federal de Santa Catarina / Empresa Brasileira de Serviços Hospitalares (HU/ UFSC/EBSERH).

\section{Authors' contributions}

$E D, R N, M C S, A F Z, I A P, M L B, F S N$ contributed to study design. ED, RN, MLB, AFZ, IAP, FSN performed clinical procedures and contributed to data collection. FHB, MCS, LKP performed laboratorial procedures and contributed to data collection. ED and FSN analyzed data and wrote the main manuscript. All authors reviewed and contributed to the final text. The author(s) read and approved the final manuscript.

\section{Funding}

There is no funding to be reported.

\section{Availability of data and materials}

The datasets used and/or analyzed during the current study are available from the corresponding author upon reasonable request.

\section{Declarations}

Ethics approval and consent to participate

The study was approved by the National Committee for Research Ethics (number 44333115.0.0000.0121). Written informed consent was obtained from all patients.

\section{Consent for publication}

All authors read and approved the final manuscript and gave their consent for publication.

\section{Competing interests}

The authors declare no conflict of interest.

\section{Author details}

${ }^{1}$ Urology Service, University Hospital Prof. Polydoro Ernani de São Thiago HU/EBSERH, Federal University of Santa Catarina (UFSC), Florianópolis, Brazil. ${ }^{2}$ Graduate Program in Medical Sciences (PPGCM), Health Sciences Center (CCS), Federal University of Santa Catarina (UFSC), Florianópolis, Brazil. ${ }^{3}$ Laboratory of Molecular Biology, Microbiology and Serology, Health Sciences Center (CCS), Federal University of Santa Catarina (UFSC),

Florianópolis, Brazil. ${ }^{4}$ Rheumatology Unit, University Hospital Prof. Polydoro Ernani de São Thiago HU/EBSERH, Federal University of Santa Catarina (UFSC), Florianópolis, Brazil. ${ }^{5}$ Internal Medicine Department, Health Sciences Center (CCS), Federal University of Santa Catarina (UFSC), Florianópolis, Brazil. ${ }^{6}$ Departamento de Clínica Médica, Hospital Universitário, Universidade Federal de Santa Catarina, $3^{\circ}$ andar, Rua Profa. Maria Flora Pausewang, Florianópolis, SC 88036-800, Brazil.

Received: 23 November 2020 Accepted: 12 April 2021

Published online: 04 May 2021

\section{References}

1. Taurog JD, Chhabra A, Colbert RA. Ankylosing Spondylitis and Axial Spondyloarthritis. N Engl J Med. 2016;374:2563-74.

2. Mason RM, Murray RS, Oates JK, Young AC. Prostatitis and ankylosing spondylitis. Br Med J. 1958;1(5073):748-51. https://doi.org/10.1136/bmj.1. 5073.748 .

3. Geirsson AJ, Eyjolfsdottir H, Bjornsdottir G, Kristjansson K, Gudbjornsson B. Prevalence and clinical characteristics of ankylosing spondylitis in Iceland - a nationwide study. Clin Exp Rheumatol. 2010;28(3):333-40.

4. Pöllänen R, Sillat T, Pajarinen J, Levón J, Kaivosoja E, Konttinen YT. Microbial antigens mediate HLA-B27 diseases via TLRs. J Autoimmun. 2009;32(3-4): 172-7. https://doi.org/10.1016/j.jaut.2009.02.010.

5. Krieger JN, Nyberg LJ, Nickel JC. NIH consensus definition and classification of prostatitis. JAMA. 1999;282(3):236-7. https://doi.org/10.1001/jama.282.3.236.

6. Meares EM, Stamey TA. Bacteriologic localization patterns in bacterial prostatitis and urethritis. Investig Urol. 1968:5(5):492-518.

7. Nickel JC, Shoskes D, Wang Y, Alexander RB, Fowler JE, Zeitlin S, et al. How does the pre-massage and post-massage 2-glass test compare to the Meares-Stamey 4-glass test in men with chronic prostatitis/chronic pelvic pain syndrome? J Urol. 2006;176(1):119-24. https://doi.org/10.1016/S00225347(06)00498-8.

8. van der Linden S, Valkenburg HA, Cats A. Evaluation of diagnostic criteria for ankylosing spondylitis. A proposal for modification of the New York criteria. Arthritis Rheum. 1984;27(4):361-8. https://doi.org/10.1002/art.17802 70401.

9. Novotny C, Deves E, Novotny R, Rodrigues IK, Neves FS. Cultural adaptation of the National Institutes of Health--chronic prostatitis symptom index $(\mathrm{NIH}-$ CPSI)--to Brazilian spoken Portuguese: NIH-CPSI (Braz). Int Braz J Urol. 2013; 39(5):683-91. https://doi.org/10.1590/S1677-5538.IBJU.2013.05.11.

10. Rodrigues Netto N Jr, de Lima ML, de Andrade EF, et al. Latin American study on patient acceptance of the international prostate symptom score (IPSS) in the evaluation of symptomatic benign prostatic hyperplasia. Urology. 1997:49(1):46-9. https://doi.org/10.1016/S0090-4295(96)00372-X.

11. Shinjo SK, Gonçalves R, Gonçalves CR. Measures of clinical assessment in patients with Ankylosing spondylitis: review of literature. Rev Bras Reumatol. 2006;46(5):340-6. https://doi.org/10.1590/S0482-50042006000500007.

12. Machado $P$, Landewé $R$, Lie $E$, et al. Ankylosing Spondylitis Disease Activity Score (ASDAS): defining cut-off values for disease activity states and improvement scores. Ann Rheum Dis. 2011;70(1):47-53. https://doi.org/1 0.1136/ard.2010.138594. 
13. Nickel JC, Downey J, Hunter D, Clark J. Prevalence of prostatitis-like symptoms in a population based study using the National Institutes of Health chronic prostatitis symptom index. J Urol. 2001;165(3):842-5. https:// doi.org/10.1016/S0022-5347(05)66541-X

14. Kunishima Y, Mori M, Kitamura H, Satoh H, Tsukamoto T. Prevalence of prostatitis-like symptoms in Japanese men: population-based study in a town in Hokkaido. Int J Urol. 2006;13(10):1286-9. https://doi.org/10.1111/ j.1442-2042.2004.01556.x.

15. Krieger JN, Lee SWH, Jeon J, Cheah PY, Liong ML, Riley DE. Epidemiology of prostatitis. Int J Antimicrob Agents. 2008;31(Suppl 1):S85-90.

16. Magistro G, Wagenlehner FM, Grabe M, Weidner W, Stief CG, Nickel JC. Contemporary Management of Chronic Prostatitis/chronic pelvic pain syndrome. Eur Urol. 2016;69(2):286-97. https://doi.org/10.1016/j.eururo.2015. 08.061 .

17. Drannik GN, Gorpinchenko II, Kurchenko Al, Gusev SN. Efficacy study of new drug Mercureid (MSC-428) in anti-TNFa therapy for chronic prostatitis. Acta Sci Cancer Biol. 2019;3:9-16.

\section{Publisher's Note}

Springer Nature remains neutral with regard to jurisdictional claims in published maps and institutional affiliations.

Ready to submit your research? Choose BMC and benefit from:

- fast, convenient online submission

- thorough peer review by experienced researchers in your field

- rapid publication on acceptance

- support for research data, including large and complex data types

- gold Open Access which fosters wider collaboration and increased citations

- maximum visibility for your research: over $100 \mathrm{M}$ website views per year

At $\mathrm{BMC}$, research is always in progress.

Learn more biomedcentral.com/submissions 